\title{
Survival and long-term outcomes after mitral valve replacement in patients aged 18 to 50 years
}

\author{
Samuel R. Schnittman, BA, ${ }^{a}$ Shinobu Itagaki, MD, MSc, ${ }^{a}$ Nana Toyoda, MD, PhD, ${ }^{\text {a }}$ David H. Adams, MD, ${ }^{a}$ \\ Natalia N. Egorova, $\mathrm{PhD},{ }^{b}$ and Joanna Chikwe, $\mathrm{MD}^{\mathrm{a}, \mathrm{c}}$
}

\section{ABSTRACT}

Objective: To provide long-term data on survival and major morbidity after mitral valve replacement in patients aged 18 to 50 years.

Methods: Retrospective analysis of 2727 patients aged 18 to 50 years who underwent isolated mitral replacement in California and New York from 1997 to 2006. Median follow-up time was 12.4 years (maximum 15.0 years). The primary endpoint was mortality; secondary endopoints were stroke, major bleeding, and reoperation. Propensity matching yielded 373 patient pairs.

Results: Bioprosthetic valve use increased from 10\% to 34\% between 1997 and $2014(P<.001)$. Among propensity score-matched patients, actuarial 15 -year survival was 74.3\% (95\% confidence interval [CI], 69.0\%-78.7\%) after bioprosthetic versus $80.8 \%$ (95\% CI, 75.1\%-85.3\%) mechanical valve replacement (hazard ratio [HR], 1.67; 95\% CI, 1.21-2.32, $P=.002$ ). At 15 years after mitral valve replacement, the cumulative incidence of stroke was similar $(9.1 \%$ [95\% CI, 6.0\%-13.0\%] vs 9.7\% [95\% CI, 6.7-13.4]; HR, 0.95 [95\% CI, $0.57-1.59])$; the cumulative incidence of major bleeding events was similar (7.9\% [95\% CI, 5.0\%-11.5\%] vs $11.5 \%$ [95\% CI, 7.6\%-16.2\%]; HR, 0.78 [95\% CI, 0.46-1.32]); and the cumulative incidence of reoperation after bioprosthetic valve replacement was greater $(19.9 \%$ [95\% CI, 15.4\%-24.8\%] vs 5.7\% [95\% CI, 3.5\%-8.7\%]; HR, 20.3 [95\% CI, 4.0-102.8]), respectively.

Conclusions: The significant survival benefit associated with mechanical mitral valve replacement in adults $\leq 50$ years may be due to the practice of implanting bioprostheses in sicker patients or those judged less likely to comply with long-term medication despite adjustment for baseline characteristics in propensity score matching. (J Thorac Cardiovasc Surg 2018;155:96-102)

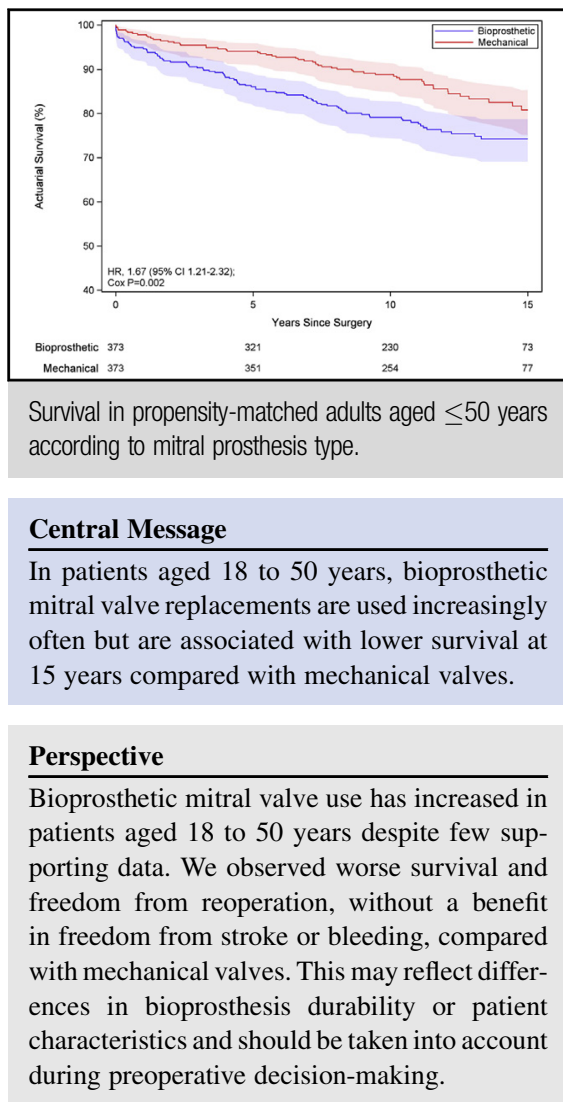

See Editorial Commentary page 103.

See Editorial page 79.
Approximately $10 \%$ of patients undergoing mitral valve replacement in the United States are adults $<50$ years of age. ${ }^{1}$ Current consensus guidelines favor mechanical over bioprosthetic valve replacement in this age group because the risks of structural valve degeneration and reoperation

From the Departments of ${ }^{\mathrm{a} C}$ Cardiovascular Surgery, and ${ }^{\mathrm{b}}$ Health Evidence and Policy, Icahn School of Medicine at Mount Sinai; and ${ }^{\mathrm{c}}$ Department of Surgery, Stony Brook University Hospital, New York, NY.

Received for publication Jan 29, 2017; revisions received July 5, 2017; accepted for publication Aug 1, 2017; available ahead of print Sept 21, 2017.

Address for reprints: Joanna Chikwe, MD, Department of Cardiovascular Surgery, Mount Sinai Hospital, 1190 Fifth Ave, New York, NY 10029 (E-mail: Joanna. Chikwe@mountsinai.org).

0022-5223/\$36.00

Copyright (C) 2017 Published by Elsevier Inc. on behalf of The American Association for Thoracic Surgery

http://dx.doi.org/10.1016/j.jtcvs.2017.08.018 associated with bioprostheses are thought to outweigh the increased risk of hemorrhagic and embolic events associated with mechanical valves and life-long anticoagulation., ${ }^{2,3}$ These recommendations are based primarily on the results of 2 randomized controlled trials that found no significant difference in late survival ${ }^{4-6}$ but that were performed during the 1970s and 1980s in older patients who predominantly underwent aortic rather than mitral valve replacement and on more recent,

Scanning this QR code will take
you to supplemental figures and
tables for this article.




\section{Abbreviations and Acronyms \\ $\mathrm{CI}=$ confidence interval \\ HR $=$ hazard ratio \\ ICD-9-CM = International Classification of \\ Diseases, 9th Revision, Clinical \\ Modification}

underpowered single-center retrospective series. ${ }^{7-12}$ We therefore analyzed a cohort of patients $\leq 50$ years of age drawn from 2 states and 171 hospitals to quantify long-term mortality, stroke, reoperation, and bleeding after mitral valve replacement according to prosthesis type, in a broad cross-section of contemporary clinical practice.

\section{METHODS}

\section{Study Design}

We identified all patients aged 18 to 50 years undergoing primary mitral valve replacement in California and New York State between January 1, 1997, and December 31, 2006. Patients were identified from 2 mandatory all-payer administrative databases: The Office of Statewide Health Planning and Development in California State and the Statewide Planning and Research Cooperative System. Both databases capture individual patient data on every hospital discharge, ambulatory surgical procedure, and emergency department visits in each state.

Exclusion criteria consisted of out-of-state residency, previous valve replacement or repair, previous heart transplantation, concomitant valve replacement or repair of any other valve, congenital cardiac history or procedures, endocarditis, and concomitant coronary artery bypass grafting (Table E1).

The International Classification of Diseases, 9th Revision, Clinical Modification (ICD-9-CM) procedure codes 35.23 and 35.24 were used to identify bioprosthetic and mechanical mitral replacements, respectively. The ICD-9-CM diagnosis codes from the index hospitalization, and all hospitalizations up to 2 years before the index hospitalization, were used to determine patient comorbid conditions at baseline (Table E2). The Program for Protection of Human Subjects at the Icahn School of Medicine at Mount Sinai, the Committee for the Protection of Human Subjects of California State, and the New York State Department of Health data protection review board approved this study with a waiver of informed consent.

\section{Study Endpoints}

All-cause mortality was the primary outcome, and the secondary outcomes were stroke, major bleeding, and mitral valve reoperation. Deaths were captured from California and New York State Vital Death Records via their respective Departments of Health. Additional death records were collected from the discharge disposition from any subsequent inpatient, emergency department, or ambulatory surgery visits, as well as from the Social Security Death Master File. Stroke during the index admission was defined as a postoperative cerebrovascular accident and in subsequent admissions as a primary diagnosis of ischemic or hemorrhagic cerebrovascular event. Transient ischemic attacks were excluded from this definition. Major bleeding was defined as a primary diagnosis of any bleeding event that required admission to hospital. Reoperation was defined as mitral valve replacement in subsequent admissions. ICD-9-CM codes were used to identify these late events (Tables E3 and E4). Patients free from death, stroke, major bleeding, or reoperation were censored on December 31, 2014.

\section{Statistical Analysis}

Means with standard deviations are used to report continuous variables, and proportions are used to report categorical variables. The Student $t$ test for normally distributed continuous variables and Pearson $\chi^{2}$ test for categorical variables as well as standardized differences for both continuous and categorical variables were used to quantify the differences in baseline characteristics between patients receiving bioprosthetic and mechanical prosthetic mitral valves. The Kolmogorov test was used to determine normality in continuous variables. Non-normal continuous variables are reported as median with interquartile ranges, and differences were tested via the Wilcoxon-Mann-Whitney test. Trend analysis was performed with the Cochran-Armitage test on patients receiving mitral valve replacements between January 1, 1997, and December 31, 2014.

To eliminate confounding due to intrinsic differences in baseline characteristics between the bioprosthetic and mechanical valve replacement cohorts, propensity score matching was performed. Propensity scores were calculated with a logistic regression with bioprosthetic valve implantation as the outcome and all patient baseline characteristics (admission urgency, index surgery year, age, sex, race, coagulation defects, hypertension, diabetes, coronary artery disease, peripheral vascular disease, cerebrovascular disease, congestive heart failure, atrial fibrillation, chronic obstructive pulmonary disease, chronic kidney disease, liver disease, cancer) included in the model as covariates. ${ }^{13,14}$ The area under the receiver operating characteristic curve for the model was 0.78 . Patients were then matched 1:1 using a caliper of 0.01 of the logit of the propensity score. Differences in baseline characteristics and 30-day complication incidence between patients in both groups were detected with the use of the paired $t$ test for normally distributed continuous variables, the Wilcoxon signed rank sum test for non-normally distributed continuous variables, and the McNemar test for categorical variables; standardized differences were also reported.

Survival curves of the primary outcome of mortality were constructed with the Kaplan-Meier method; prostheses were compared with a marginal Cox model with a robust sandwich variance estimator.

Competing risk analysis of the secondary outcomes-stroke, major bleeding, and reoperation-was performed by creating cumulative incidence functions. For each end point, adjusted hazard ratios were calculated with Cox proportional hazards models. The proportional hazards assumption was assessed in each model and found to be intact except reoperation and, if violated, the hazard ratios at different follow-up time points were reported.

To assess the robustness of the findings, all analyses were repeated in the full patient cohort as a sensitivity analysis using multivariable analysis with marginal Cox models with robust sandwich variance estimators controlling for admission urgency, index surgery year, age, sex, race, coagulation defects, hypertension, diabetes, coronary artery disease, peripheral vascular disease, cerebrovascular disease, congestive heart failure, atrial fibrillation, chronic obstructive pulmonary disease, chronic kidney disease, liver disease, cancer, and clustering of patients within hospitals. All these sensitivity analyses confirmed the main findings and were included in the supplementary documents (Table E5).

All statistical tests were 2-tailed and an alpha level of 0.05 considered statistically significant. Statistical analyses were carried out with SAS version 9.4 (SAS Institute Inc, Cary, NC).

\section{RESULTS}

\section{Study Population}

We identified 5818 patients aged 18 to 50 years who underwent mitral valve replacement. After excluding patients from out-of-state $(4.9 \%, \mathrm{n}=282)$ and with previous valve replacement or repair $(6.8 \%, \mathrm{n}=398)$, previous heart transplant $(<0.3 \%, \mathrm{n}<15)$, concomitant valve replacement or repair $(26.1 \%, \mathrm{n}=1520)$, congenital cardiac history or procedure $(2.5 \%, \mathrm{n}=145)$, endocarditis $(18.8 \%, \mathrm{n}=1095)$, and concomitant coronary artery bypass grafting $(9.4 \%, \mathrm{n}=544)$, the study cohort 
TABLE 1. Patient baseline characteristics after propensity score matching, by type of prosthesis

\begin{tabular}{|c|c|c|c|c|}
\hline Baseline characteristics & $\begin{array}{l}\text { Bioprosthetic } \\
(\mathbf{N}=\mathbf{3 7 3})\end{array}$ & $\begin{array}{c}\text { Mechanical } \\
(N=373)\end{array}$ & Standardized difference, $\%$ & $P$ value \\
\hline \multicolumn{5}{|l|}{ Demographics } \\
\hline Age, median [IQR], y & $42[36-47]$ & $42[36-47]$ & 10.8 & .12 \\
\hline $18-30$ & $57(15.3)$ & $49(13.1)$ & & .68 \\
\hline $31-40$ & $105(28.2)$ & $98(26.3)$ & & \\
\hline $41-50$ & $211(56.6)$ & $226(60.6)$ & & \\
\hline Men & $134(35.9)$ & $140(37.5)$ & 3.3 & 64 \\
\hline New York State resident & $227(60.9)$ & $211(56.6)$ & 8.7 & .23 \\
\hline \multicolumn{5}{|l|}{ Race } \\
\hline White (non-Hispanic) & $180(48.3)$ & $183(49.1)$ & 1.6 & .99 \\
\hline African-American (non-Hispanic) & $72(19.3)$ & $71(19.0)$ & 0.7 & \\
\hline Other & $121(32.4)$ & $119(31.9)$ & 1.2 & \\
\hline Emergent/urgent admission & $162(43.4)$ & $144(38.6)$ & 9.8 & .15 \\
\hline \multicolumn{5}{|l|}{ Comorbidities } \\
\hline Coagulation/platelet disorders & $20(5.4)$ & $20(5.4)$ & 0.0 & 1.00 \\
\hline Hypertension & $100(26.8)$ & $103(27.6)$ & 1.8 & .81 \\
\hline Diabetes mellitus & $26(7.0)$ & $28(7.5)$ & 2.1 & .78 \\
\hline Coronary artery disease & $74(19.8)$ & $66(17.7)$ & 5.5 & .46 \\
\hline Peripheral vascular disease & $6(1.6)$ & $5(1.3)$ & 2.2 & .76 \\
\hline Cerebrovascular disease & $37(9.9)$ & $29(7.8)$ & 7.6 & .29 \\
\hline Congestive heart failure & $189(50.7)$ & $191(51.2)$ & 1.1 & .88 \\
\hline Atrial fibrillation & $77(20.6)$ & $94(25.2)$ & 10.9 & .12 \\
\hline Chronic obstructive pulmonary disease & $76(20.4)$ & $69(18.5)$ & 4.7 & .49 \\
\hline Chronic kidney disease & $23(6.2)$ & $26(7.0)$ & 3.3 & .66 \\
\hline Dialysis dependent & $17(4.6)$ & $17(4.6)$ & 0.0 & 1.00 \\
\hline Liver disease & $15(4.0)$ & $22(5.9)$ & 8.7 & .25 \\
\hline Cancer & $15(4.0)$ & $10(2.7)$ & 7.5 & .30 \\
\hline \multicolumn{5}{|l|}{ Year of surgery } \\
\hline 1997 & $24(6.4)$ & $35(9.4)$ & 10.9 & .22 \\
\hline 1998 & $23(6.2)$ & $22(5.9)$ & 1.1 & \\
\hline 1999 & $33(8.8)$ & $27(7.2)$ & 5.9 & \\
\hline 2000 & $29(7.8)$ & $39(10.5)$ & 9.3 & \\
\hline 2001 & $34(9.1)$ & $40(10.7)$ & 5.4 & \\
\hline 2002 & $48(12.9)$ & $35(9.4)$ & 11.1 & \\
\hline 2003 & $43(11.5)$ & $28(7.5)$ & 13.7 & \\
\hline 2004 & 48 (12.9) & $55(14.7)$ & 5.4 & \\
\hline 2005 & $42(11.3)$ & $60(16.1)$ & 14.1 & \\
\hline 2006 & $49(13.1)$ & $32(8.6)$ & 14.7 & \\
\hline
\end{tabular}

$I Q R$, Interquartile range.

comprised 2727 patients who underwent either bioprosthetic $(14.0 \%, \mathrm{n}=382)$ or mechanical $(86.0 \%$, $\mathrm{n}=2345)$ mitral valve replacement. Propensity score matching yielded 373 patient pairs. The maximum follow-up time was 15.0 years (median 12.4 years).

\section{Patient Characteristics}

Use of bioprosthetic mitral replacements increased from $10.1 \%$ in 1997 to $33.6 \%$ in $2014(P<.001$; Figure E1). Patients who received bioprosthetic valves had a greater prevalence of emergent/urgent admission $(39.0 \%$ vs $26.6 \%, P<.001)$ but a lower prevalence of atrial fibrillation $(24.6 \%$ vs $34.8 \%, P<.001)$ (Table E6). In the propensity score-matched groups, there were no significant differences in patient characteristics (Table 1) or 30-day outcomes after bioprosthetic versus mechanical valve replacement, suggesting that these groups were well matched (Table 2).

\section{Survival}

We observed a significant difference in long-term survival between bioprosthetic and mechanical mitral valves in the propensity score-matched groups (Figure 1). Actuarial 5-, 10-, and 15-year survival were $86.1 \%(95 \%$ confidence interval $[\mathrm{CI}], 82.1 \%-89.2 \%), 79.1 \%(95 \%$ CI, $74.6 \%-83.0 \%$ ), and $74.3 \%$ (95\% CI, $69.0 \%-78.7 \%)$ in the bioprosthetic group compared with $94.1 \%(95 \%$ CI, 91.2\%-96.1\%), 88.8\% (95\% CI, 85.1\%-91.6\%), and $80.8 \%$ (95\% CI, $75.1 \%-85.3 \%)$ in the mechanical group 
TABLE 2. Thirty-day outcomes after mitral valve replacement in propensity score-matched patients, by type of prosthesis

\begin{tabular}{|c|c|c|c|c|}
\hline \multirow[b]{2}{*}{ Patient cohort } & \multirow[b]{2}{*}{ Outcome } & \multicolumn{2}{|c|}{ Prosthesis type, n (\%) } & \multirow[b]{2}{*}{$P$ value } \\
\hline & & Bioprosthetic $(n=373)$ & Mechanical $(n=373)$ & \\
\hline \multirow[t]{5}{*}{ Propensity score-matched patients } & Mortality & $10(2.7)$ & $3(0.8)$ & .05 \\
\hline & Stroke & $3(0.8)$ & $4(1.1)$ & .71 \\
\hline & Atrial fibrillation & $54(14.5)$ & $52(13.9)$ & .84 \\
\hline & Acute kidney injury & $15(4.0)$ & $11(3.0)$ & .41 \\
\hline & Respiratory failure & 40 (10.7) & $45(12.1)$ & .56 \\
\hline
\end{tabular}

(hazard ratio [HR], 1.67; 95\% CI, 1.21-2.32, $P=.002$ ) in the propensity score-matched cohort, respectively. There was a similar survival benefit associated with mechanical valves in the overall cohort (HR, 1.39; 95\% CI, $1.05-1.83, P=.02$ ). respectively (Table E5). In analysis of each age group, no survival benefit was observed in mechanical valve between age 18 to 30 and 31 to 40 years, but patients who had mechanical valve had significantly better survival than patients with bioprosthetic valve between age 41 and 50 (Figure E2).

\section{Stroke}

There was no significant difference in the risk-adjusted cumulative incidence of stroke between bioprosthetic and mechanical mitral valves at 15 years in the propensity score-matched cohort. In the propensity score-matched cohort, the cumulative incidence of stroke at 5,10 , and 15 years was $4.8 \%(95 \%$ CI, 3.0\%-7.3\%), $7.1 \%(95 \%$ CI, $4.8 \%-10.0 \%)$, and $9.1 \%(95 \% \mathrm{CI}, 6.0 \%-13.0 \%)$ in patients who underwent bioprosthetic mitral valve replacement versus 5.4\% (95\% CI, 3.4\%-8.0\%), 8.9\% $(95 \% \quad$ CI, $\quad 6.2 \%-12.1 \%), \quad$ and $\quad 9.7 \% \quad(95 \% \quad$ CI, 6.7\%-13.4\%) in patients who underwent mechanical mitral valve replacement, respectively (HR, $0.95 ; 95 \% \mathrm{CI}$, 0.57-1.59) (Figure 2, A). The 30-day mortality after stroke was $5.3 \%$. The results of the multivariable analysis of stroke in the full patient cohort are shown in Table E5.

\section{Major Bleeding}

There was no significant difference in the risk-adjusted cumulative incidence of major bleeding between bioprosthetic and mechanical valves at 15 years in the propensity score-matched cohort. The cumulative incidence of bleeding in the overall cohort at 5, 10, and 15 years was $4.3 \%(95 \% \mathrm{CI}, 2.6 \%-6.7 \%), 5.9 \% \quad(95 \% \mathrm{CI}$, $3.8 \%-8.6 \%)$, and $7.9 \%(95 \%$ CI, $5.0 \%-11.5 \%)$ in patients who underwent bioprosthetic mitral valve replacement versus $4.6 \%(95 \% \mathrm{CI}, 2.8 \%-7.0 \%), 8.4 \%(95 \% \mathrm{CI}$,

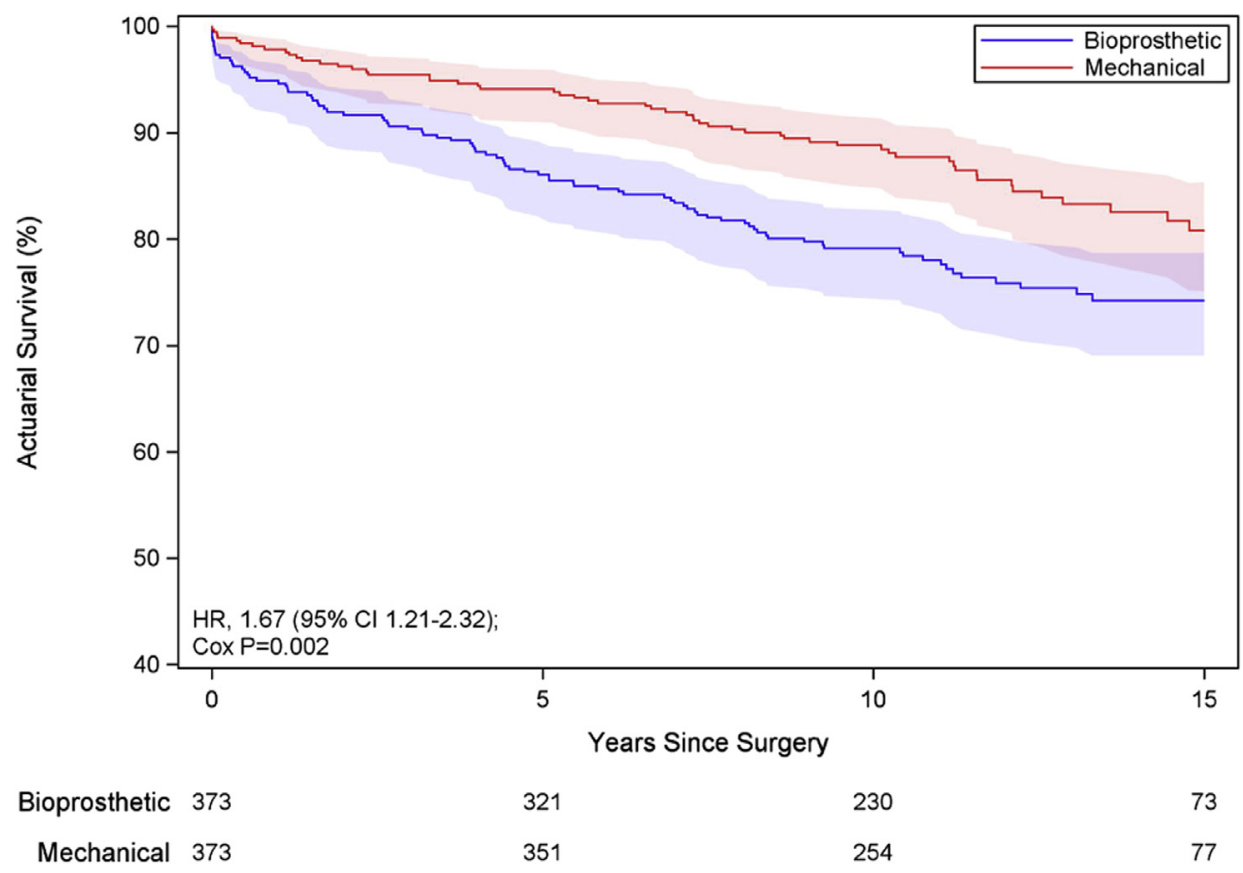

FIGURE 1. Kaplan-Meier survival curves in propensity score-matched patients aged 18 to 50 years after mitral valve replacement. $H R$, Hazard ratio; CI, confidence interval. 

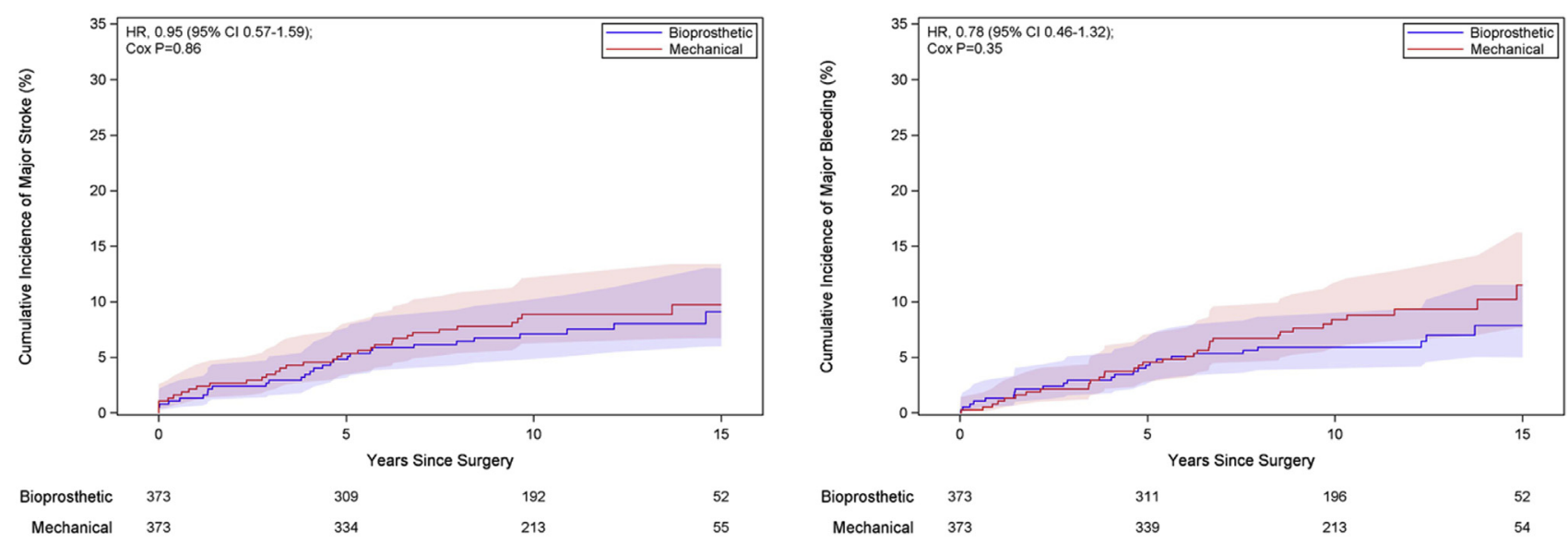

A

B

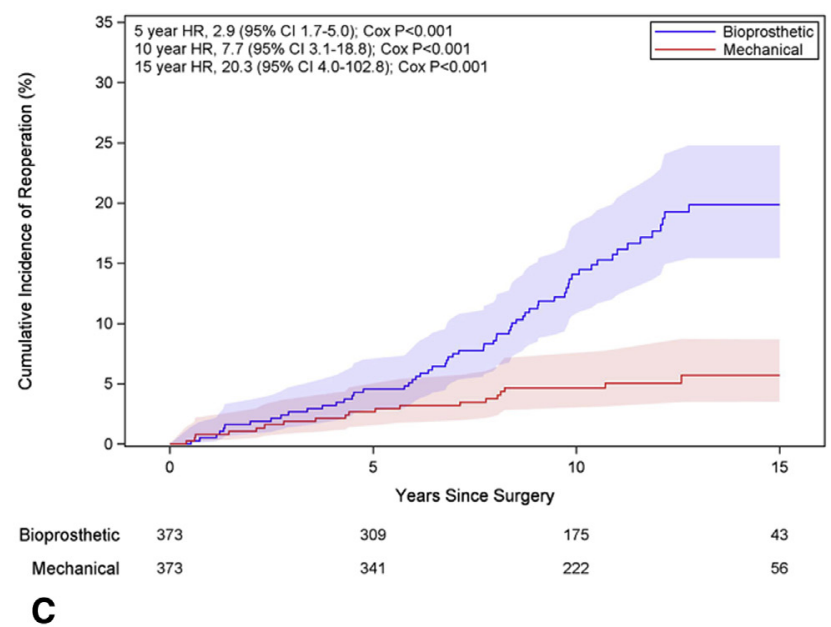

FIGURE 2. Cumulative incidence of major morbidity in propensity score-matched patients aged 18 to 50 years after mitral valve replacement according to prosthesis type: A, stroke; $\mathrm{B}$, major bleeding; and $\mathrm{C}$, reoperation. $H R$, Hazard ratio; $C I$, confidence interval.

$5.8 \%-11.6 \%)$, and $11.5 \%$ (95\% CI, $7.6 \%-16.2 \%)$ in patients who underwent mechanical mitral valve replacement, respectively ( $\mathrm{HR}, 0.78 ; 95 \% \mathrm{CI}, 0.46-1.32)$ (Figure 2, B). The 30-day mortality after major bleeding was $6.8 \%$. The results of the multivariate analysis of major bleeding in the full patient cohort are shown in Table E5.

\section{Reoperation}

Mechanical valves were associated with a significantly lower rate of mitral valve reoperation than bioprosthetic valves in the propensity score-matched cohort. The cumulative incidence of mitral valve reoperation in the propensity score-matched cohort at 5, 10, and 15 years in patients with bioprosthetic mitral valves was $4.6 \%$ (95\% CI, $2.8 \%-7.0 \%), 14.1 \%(95 \%$ CI, $10.6 \%-18.0 \%)$, and $19.9 \%(95 \%$ CI, $15.4 \%-24.8 \%)$ versus $2.7 \%(95 \% \mathrm{CI}$, $1.4 \%-4.7 \%$ ), $4.7 \%$ (95\% CI, $2.8 \%-7.2 \%$ ), and $5.7 \%$ (95\% CI, 3.5\%-8.7\%) in patients with mechanical valves, respectively (adjusted HR at 15 years 20.3; 95\% CI,
4.0-102.8) (Figure 2, C). An overall 30-day mortality after reoperation was $2.5 \%$. The results of the multivariable analysis of reoperation in the full patient cohort are shown in Table E5.

\section{DISCUSSION}

This study provides long-term data on survival and major morbidity after mitral valve replacement in young adults from a broad cross-section of contemporary clinical practice. Our data show first that up to one third of patients aged $\leq 50$ years undergoing mitral valve replacement receive bioprosthetic valves and second the much greater risk of reoperation does not appear to be offset by any reduction in stroke and major bleeding rates compared with mechanical valves. The poorer survival that we observed in patients who received bioprosthetic valves confirms the findings of much smaller retrospective studies..$^{9-11}$

Studies comparing bioprosthetic with mechanical mitral valve replacement in this age group previously have been 
limited to single-center retrospective studies, with conflicting results regarding both the comparative risks of reoperation and survival. For example, Kaneko and colleagues $^{10}$ reported better survival and freedom from reoperation at 15 years with mechanical mitral valve replacement over bioprosthetic in 125 propensity-matched patients pairs $<65$ years of age, whereas others have observed no significant differences in long-term survival. ${ }^{8,12}$ The comprehensive patient level data and large size of our cohort, which represents contemporary practice across 2 large states and 171 institutions, allowed us to adjust for key patient and provider characteristics, confirmed by the very similar 30-day outcomes in the mechanical and bioprosthetic propensity score-matched patient groups.

There are several potential explanations for our observation of a survival benefit with mechanical mitral valves. First, despite propensity matching, the likelihood remains that we are comparing substantially different patient populations. This is because of the established practice of implanting bioprosthetic valves in patients with reduced life expectancy or in patients judged unlikely to comply with life-long anticoagulation., ${ }^{2,3}$ Without patient-level data on these specific aspects of decision making, these important factors cannot be adjusted for retrospectively, potentially explaining why smaller retrospective studies show significantly worse survival in recipients of bioprosthetic valves.

The second potential reason for the reduced survival associated with bioprosthetic valves is the accelerated structural valve degeneration seen in the mitral position in younger patients. ${ }^{6}$ This means that young patients with bioprosthetic mitral valves bear an earlier burden of severe valvulopathy and reoperation which, in the absence of any survival benefits from reduced stroke and major bleeding events, may be an important determinant of their worse survival. In our propensity score-matched cohort, the cumulative incidence of reoperation was $19.9 \%$ in bioprosthetic patients versus $5.7 \%$ in mechanical patients. These results are well known: Kaneko and colleagues, ${ }^{10}$ Carrel and colleagues, ${ }^{7}$ and Ruel and colleagues ${ }^{15}$ all report high rates of structural valve degeneration and replacement among these younger patients. The implications of these data are greatest for patients unable or unwilling to comply with long-term anticoagulation. The commonest reasons for this in young patients are difficulty accessing health care and child-bearing, rather than comorbid contraindications to anticoagulation. ${ }^{16}$ These considerations are particularly relevant for patients from low- and middle-income countries where rheumatic valve disease is more prevalent in young women and long-term access to health care is less readily available. ${ }^{17}$ For many patients without reliable access to health care, and particularly those considering pregnancy, the immediate safety profile of bioprosthetic valves outweighs the risks posed by accelerated structural degeneration. Although these bioprosthetic valves are accompanied by significantly high rates of reoperation, only the placement of a bioprosthetic valve will allow for a potential future valve-in-valve replacement. It would be difficult to counsel patients on the merits of a bioprosthetic valve in the hopes of a future valve-in-valve rescue, as this emerging technology's applicability and durability remain to be seen in younger, lower-risk patients. ${ }^{18}$

\section{Limitations}

Although this study represents a broad sample of contemporary practice in North America and provides valuable long-term outcome data, there are substantial limitations in how these data can be interpreted. This is primarily because, as described previously, selection bias cannot be adequately controlled for retrospectively in young patients undergoing mitral valve replacement without more information on the rationale for valve choice. Residual confounding may exist even after propensity score matching. Second, the data are abstracted from clinical records by administrative coders and provide limited information on the etiology, severity, and sequelae of valve disease and comorbidities and no data on the model or size of each valve prosthesis beyond whether it is mechanical or bioprosthetic. Third, the number of patients at risk at 15 years is relatively small. Fourth, we may have underestimated the rate of the secondary endpoints because identifying them depends on patients remaining within their state; nevertheless, we believe that this equally affects both groups and does not diminish the study's comparative value. Finally, the follow-up available to us does not fully represent the relative lifetime risks in this patient age group. Combining this with data from additional states or national clinical datasets may allow a more definitive analysis of outcomes in this patient population that is likely to remain underrepresented in clinical trials.

\section{CONCLUSIONS}

In adults $\leq 50$ years who undergo mitral replacement, the much greater risk of reoperation with bioprosthetic valves is not mitigated by a reduction in stroke and major bleeding rates compared to mechanical valves. The significant survival benefit that we observed with mechanical mitral valve replacement may be due to accelerated structural degeneration in mitral bioprostheses. These findings should inform decision-making in patients, particularly those basing prosthesis selection on lifestyle choices rather than access to health care or contraindications to lifelong anticoagulation.

\section{Conflicts of Interest Statement}

Dr Chikwe received speaker honoraria from Edwards Lifesciences. The Icahn School of Medicine at Mount Sinai 
receives royalty payments from Edwards Lifesciences and Medtronic for intellectual property related to Dr Adams' involvement in the development of 2 mitral valve repair rings and 1 tricuspid valve repair ring. Dr Adams is the National Co-Principal Investigator of the CoreValve United States Pivotal Trial, which is supported by Medtronic. None of the sponsoring organizations had any role in the design and conduct of the study; collection, management, analysis, and interpretation of the data; preparation, review, or approval of the manuscript; or decision to submit the manuscript for publication. All other authors have nothing to disclose with regard to commercial support.

\section{References}

1. Data from the Agency for Healthcare Research and Quality Healthcare Cost and Utilization Project on line query system. Available at: hcupnet.ahrq.gov/ HCUPnet.jsp. Accessed October 25, 2016.

2. Nishimura RA, Otto CM, Bonow RO, Carabello BA, Erwin JP III, Fleisher LA, et al. 2017 AHA/ACC Focused Update of the 2014 AHA/ACC Guideline for the Management of Patients With Valvular Heart Disease: A Report of the American College of Cardiology/American Heart Association Task Force on Clinical Practice Guidelines. Circulation. 2017;135:e1159-95.

3. Vahanian A, Alfieri O, Andreotti F, Antunes MJ, Baron-Esquivias G, Baumgartner H, et al. Guidelines on the management of valvular heart disease (version 2012) The Joint Task Force on the Management of Valvular Heart Disease of the European Society of Cardiology (ESC) and the European Association for Cardio-Thoracic Surgery (EACTS). Eur J Cardiothorac Surg. 2012;42:S1-44.

4. Oxenham H, Bloomfield P, Wheatley DJ, Lee RJ, Cunningham J, Prescott RJ, et al. Twenty year comparison of a Bjork-Shiley mechanical heart valve with porcine bioprostheses. Heart. 2003;89:715-21.

5. Hammermeister K, Sethi GK, Henderson WG, Grover FL, Oprian C, Rahimtoola SH. Outcomes 15 years after valve replacement with a mechanical versus a bioprosthetic valve: final report of the Veterans Affairs randomized trial. J Am Coll Cardiol. 2000;36:1152-8.

6. Grunkemeier GL, Li HH, Naftel DC, Starr A, Rahimtoola SH. Long-term performance of heart valve prostheses. Curr Probl Cardiol. 2000;25: 73-154.
7. Carrel TP, Englberger L. Mechanical versus bioprosthetic mitral valve replacement in patients younger than 65 years. J Thorac Cardiovasc Surg. 2014;147:853-4.

8. Cen YY, Glower DD, Landolfo K, Lowe JE, Davis RD, Wolfe WG, et al. Comparison of survival after mitral valve replacement with biologic and mechanical valves in 1139 patients. J Thorac Cardiovasc Surg. 2001;122:569-77.

9. Badhwar V, Ofenloch HC, Rovin JD, van Gelder HM, Jacobs JP. Noninferiority of closely monitored mechanical valves to bioprostheses overshadowed by early mortality benefit in younger patients. Ann Thorac Surg. 2012;93:748-53.

10. Kaneko T, Aranki S, Javed Q, McGurk S, Shekar P, Davidson M, et al. Mechanical versus bioprosthetic mitral valve replacement in patients $<65$ years old. J. Thorac Cardiovasc Surg. 2014;147:117-26.

11. Daneshmand MA, Milano CA, Rankin S, Honeycutt EF, Shaw LK, Davis RD, et al. Influence of patient age on procedural selection in mitral valve surgery. Ann Thorac Surg. 2010;90:1479-86.

12. Ruel M, Kulik A, Lam BK, Rubens FD, Hendry PJ, Masters RG, et al. Long-term outcomes of valve replacement with modern prostheses in young adults. Eur $J$ Cardiothorac Surg. 2005;27:425-33.

13. Rosenbaum PR, Rubin DB. The central role of the propensity score in observational studies for causal effects. Biometrika. 1983;70:41-55.

14. Chikwe J, Chiang YP, Egorova NN, Itagaki S, Adams DH. Survival and outcomes following bioprosthetic vs mechanical mitral valve replacement in patients aged 50 to 69 years. JAMA. 2015;313:1435-42.

15. Ruel M, Chan V, Bédard P, Kulik A, Ressler L, Lam BK, et al. Very long-term survival implications of heart valve replacement with tissue versus mechanical prostheses in adults $<60$ years of age. Circulation. 2007;1156. I-294-I-300.

16. Johnston JA, Cluxton RJ, Heaton PC, Guo JJ, Moomaw CJ, Eckman MH. Predictors of warfarin use among Ohio Medicaid patients with new-onset nonvalvular atrial fibrillation. Arch Intern Med. 2003;163:1705-10.

17. Zuhlke L, Engel ME, Karthikeyan G, Rangarajan S, Mackie P, Cupido B, et al. Characteristics, complications, and gaps in evidence based interventions in rheumatic heart disease: the Global Rheumatic Heart Disease Registry (the REMEDY study). Eur Heart J. 2015;36:1115-22.

18. Muller DWM, Farivar RS, Jansz P, Bae R, Walters D, Clarke A, et al. Transcatheter mitral valve replacement for patients with symptomatic mitral regurgitation: a global feasibility trial. J Am Coll Cardiol. 2017;69:381-91.

Key Words: mitral valve, mitral valve replacement, nonelderly patients, prosthetic valve choice, long-term outcomes 


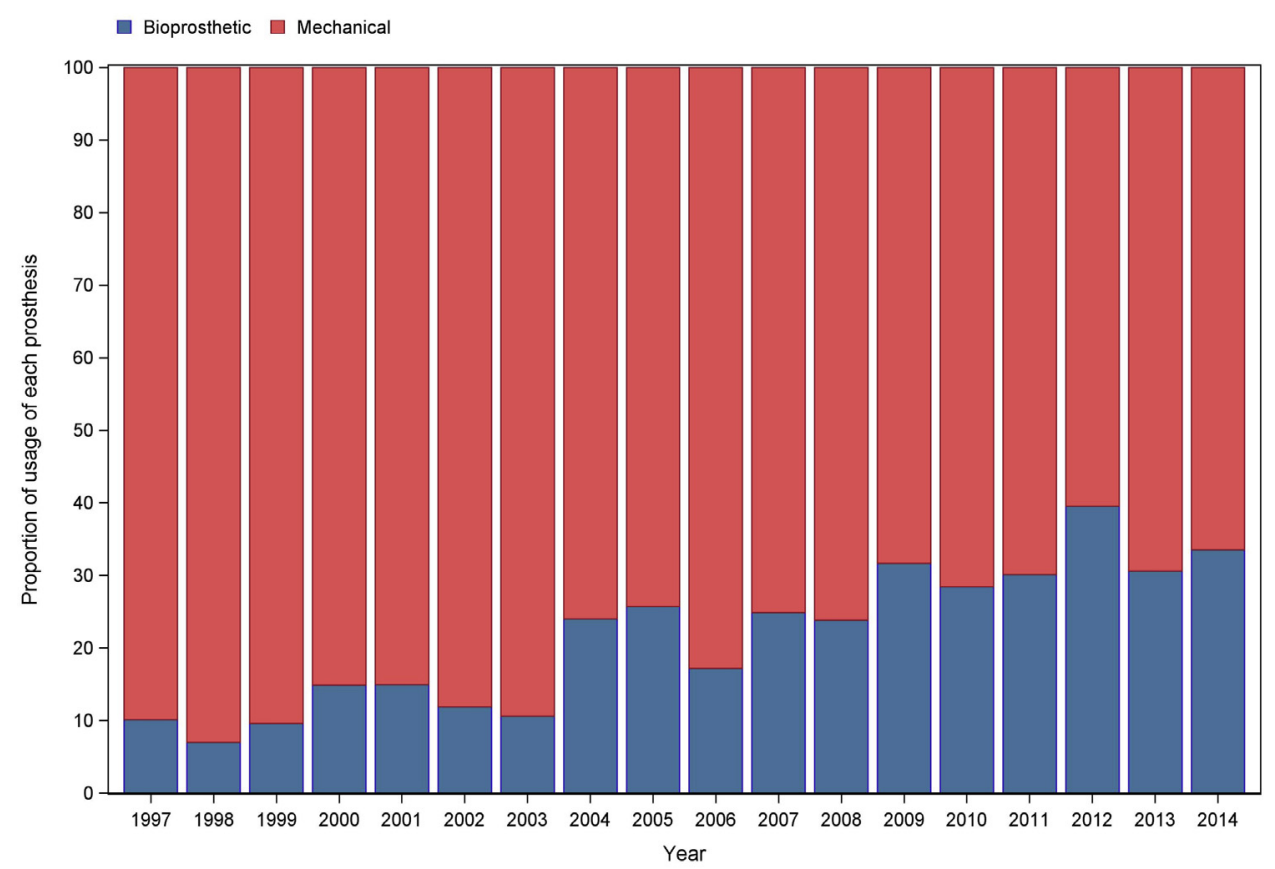

FIGURE E1. Trend in mechanical or bioprosthetic valve usage for mitral valve replacement in patients aged 18 to 50 years' $P$ value for trend calculated by the Cochran-Armitage test was $<.001$. 

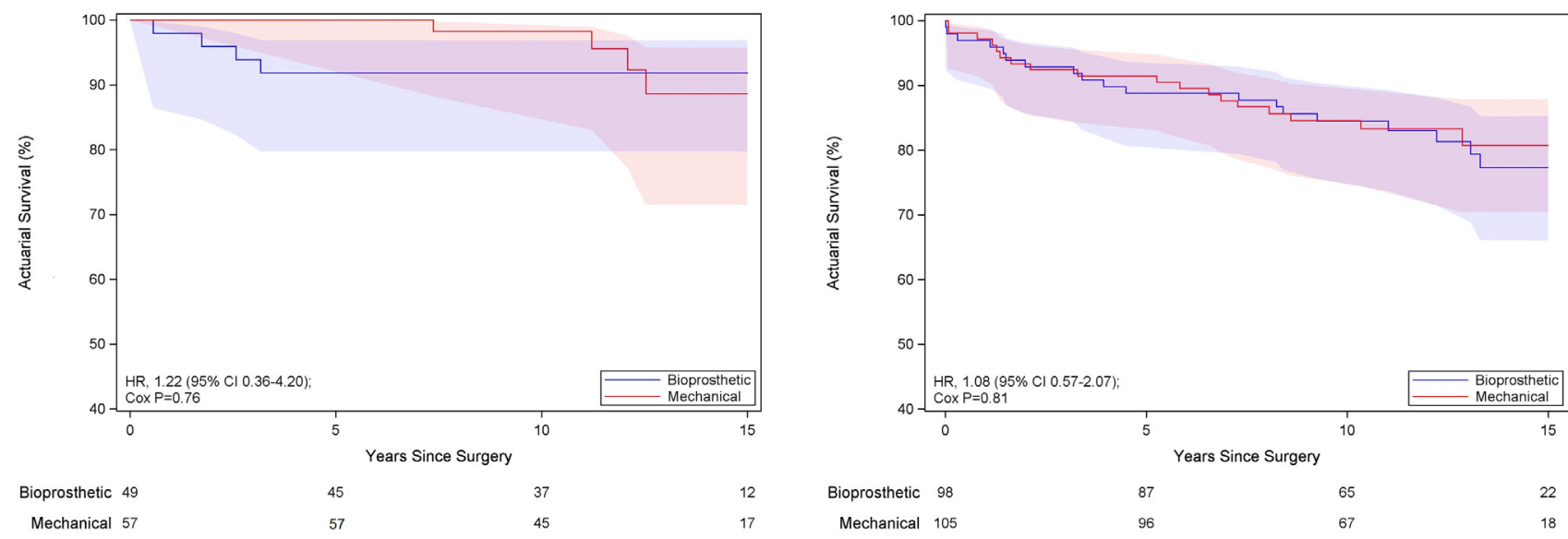

A

B

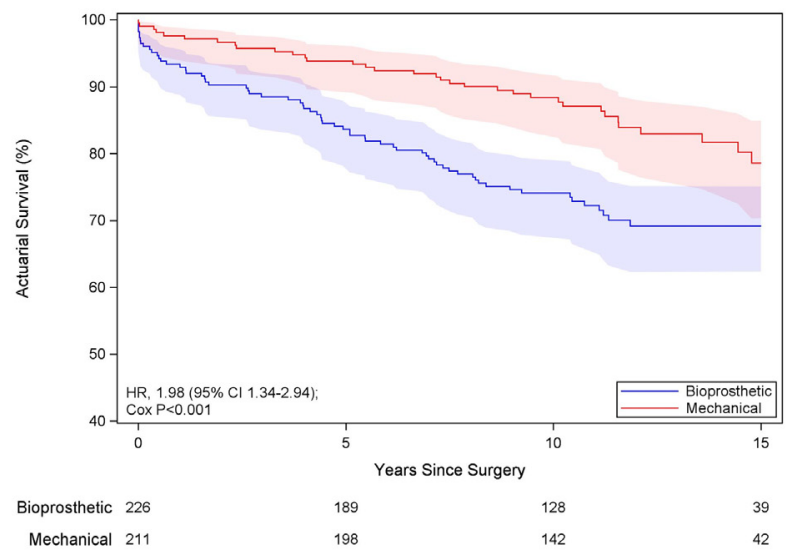

C

FIGURE E2. Survival curves in propensity score-matched patients aged 18 to 50 years according to the prosthesis type stratified by age: A, 18 to 30 years; B, 31 to 40 years; C, 41 to 50 years. $H R$, Hazard ratio; $C I$, confidence interval. 
TABLE E1. Definitions of exclusion criteria

\begin{tabular}{|c|c|}
\hline Exclusion criterion & International Classification of Diseases, 9th Edition, Clinical Modification codes \\
\hline Endocarditis & $\begin{array}{l}\text { Diagnosis codes (from index and previous admission) } \\
421,4210,4211,4219,11281,03642,09884,11504,11514 \text {, and } 11594\end{array}$ \\
\hline Previous valve replacement & $\begin{array}{l}\text { Diagnosis code (from index admission) } \\
\text { V433 } \\
\text { Procedure codes (from previous admissions) } \\
3520,3521,3522,3523,3524,3525,3526,3527 \text {, and } 3528\end{array}$ \\
\hline Previous valve repair & $\begin{array}{l}\text { Procedure codes (from previous admissions) } \\
3510,3511,3512,3513,3514, \text { and } 3533\end{array}$ \\
\hline Previous heart transplant & $\begin{array}{l}\text { Procedure codes (from index and previous admissions) } \\
336,3751 \\
\text { Diagnosis codes (from index and previous admissions) } \\
\text { V421, } 99683\end{array}$ \\
\hline Congenital cardiac disease & $\begin{array}{l}\text { Diagnosis code (from index and previous admission) } \\
7450,7451,74510,74511,74512,74519,7451,7453,7467,7457,7456,74560,74561,74569 \text {, } \\
\quad 7460,74601,74602,74609,7461,7462,7473,7474,74740,74741,74742,74749,7458 \text {, } \\
\quad 7459,7475,7468,74681,74682,74683,74684,74689,7469,7479 \text {, and V1365 } \\
\text { Procedure codes (from previous admission) } \\
354,3541,3542,3553,3554,3562,3563,3573,358,3581,3582,3583,3584,359,3591,3592, \\
\quad 3593,3594,3595,3598,3599,390 \text {, and } 3921\end{array}$ \\
\hline Concomitant congenital cardiac surgery & $\begin{array}{l}\text { Procedure codes (from index admission) } \\
354,3541,3542,3553,3554,3562,3563,3573,358,3581,3582,3583,3584,359,3591,3592 \text {, } \\
\quad 3593,3594,3595,3598,3599,390 \text {, and } 3921\end{array}$ \\
\hline Concomitant valve replacement & $\begin{array}{l}\text { Procedure codes (from index admission) } \\
3520,3521,3522,3525,3526,3527 \text {, and } 3528\end{array}$ \\
\hline Concomitant coronary artery bypass graft surgery & $\begin{array}{l}\text { Procedure codes (from index admission) } \\
361,3610,3611,3612,3613,3614,3615,3615,3617 \text {, and } 3618\end{array}$ \\
\hline
\end{tabular}


TABLE E2. Definitions of baseline characteristics

\begin{tabular}{|c|c|}
\hline Baseline characteristic & International Classification of Diseases, 9th Edition, Clinical Modification codes \\
\hline $\begin{array}{l}\text { Coagulation or } \\
\text { platelet disorders }\end{array}$ & $\begin{array}{l}\text { Diagnosis codes (from index and previous admissions) } \\
\text { 286, 2861-2865, 28652, 28653, 28659, 2866, 2867, 2869, 287, 2870-2873, 28730, 28731, 28732, 28733, 28739, } \\
\quad 2874,2875,2878 \text {, and } 2879\end{array}$ \\
\hline Hypertension & $\begin{array}{l}\text { Diagnosis codes (from index and previous admissions) } \\
\text { 401, 4011, 4019, 402, 4020, 40200, 40201, 4021, 4029, 40290, 40291, 403, 4030, 40300, 40301, 4031, 40310, } \\
\quad 40311,4039,40390,40391,404,4040,40400,40401,40402,40403,4041,40410,40411,40412,40413,4049 \text {, } \\
\quad 40490,40491,40492,40493,405,4050,40501,40509,4051,40511,40519,4059,40591,40599 \text {, and } 4372\end{array}$ \\
\hline Diabetes & $\begin{array}{l}\text { Diagnosis codes (from index and previous admissions) } \\
249,2490,24900,24901,2491,24910,24911,2492,24920,24921,2493,24930,24931,2494,24940,24941, \\
2495,24950,24951,2496,24960,24961,2497,24970,24971,2498,24980,24981,2499,24990,24991,250, \\
2500,25000,25001,25002,25003,2501,25010,25011,25012,25013,2502,25020,25021,25022,25023, \\
2503,25030,25031,25032,25033,2504,25040,25041,25042,25043,2505,25050,25051,25052,25053, \\
2506,25060,25061,25062,25063,2507,25070,25071,25072,25073,2508,25080,25081,25082,25083, \\
2509,25090,25091,25092 \text {, and } 25093\end{array}$ \\
\hline Coronary artery disease & $\begin{array}{l}\text { Un-revascularized } \\
\text { Diagnosis codes (from index and previous admissions) } \\
410,4100,41000,41001,41002,4101,41010,41011,41012,4012,40120,41021,41022,4103,41030,41031, \\
\quad 41032,4104,41040,41041,41042,4105,41050,41051,41052,4106,41060,41061,41062,4107,41070, \\
\quad 41071,41072,4108,41080,41081,41082,4109,41090,41091,41092,411,4110,4111,4118,41181,41189, \\
\quad 412,413,4130,4131,4139,414,4140,41400,41401,41402,41403,41404,41405,41406,41407,4142,4143, \\
\quad 4144,4295,4296,4297,42971 \text {, and } 42979 \\
\text { Previous percutaneous coronary intervention } \\
\text { Diagnosis codes (from index and previous admissions) } \\
\text { V4582 } \\
\text { Procedure codes (from previous admissions) } \\
\text { 0066, } 1755,3601,3602,3603,3604,3605,3606,3607,3608, \text { and } 3609 \\
\text { Previous coronary artery bypass grafting } \\
\text { Diagnosis codes (from index and previous admissions) } \\
\text { V4581 } \\
\text { Procedure codes (from previous admissions) } \\
3610,3611,3612,3613,3614,3615,3616,3617 \text {, and } 3619\end{array}$ \\
\hline
\end{tabular}

Peripheral vascular disease

Diagnosis codes (from index and previous admissions)

4400, 4401, 4402, 44020, 44021, 44022, 44023, 44024, 44029, 4403, 44030, 44031, 44032, 4404, 4408, 4409, 4471, 9961, 99662, 99674, and V434

$\begin{array}{ll}\text { Cerebrovascular disease } & \text { Diagnosis codes (from index and previous admissions) } \\ 3623,36230,36231,36232,36233,36234,36235,36236,36237,3466,34660,34661,34662,34663,430,431, \\ & 432,4320,4321,4329,433,4330,43300,43301,4331,43310,43311,4332,43320,43321,4333,43330, \\ & 43331,4338,43380,43381,4339,43390,43391,434,4340,43400,43401,4341,43410,43411,4349,43490, \\ & 43491,435,4350,4351,4352,4353,4358,4359,436,437,4370,4371,4372,4373,4374,4375,4376,4377, \\ & 99702,4378,4379,438,4380,4381,43810,43811,43812,43813,43814,43819,4382,43820,43821,43822, \\ & 4383,43830,43831,43832,4384,43840,43841,43842,4385,43850,43851,43852,4386,4387,4388,43881, \\ & 43882,43883,43884,43885,43889, \text { and } 4389 \\ \text { Congestive heart failure } & \text { Diagnosis codes (from index and previous admissions) } \\ & 39891,428,4280,4281,4282,42820,42821,42822,42823,4283,42830,42831,42832,42833,4284,42840, \\ & 42841,42842,42843,4289,429,4290,4291,4292,4293,4294,4295,4296,4297,42971,42979,4298,42981, \\ \text { Atrial fibrillation } & 42982,42983,42989, \text { and } 4299 \\ \text { Chronic obstructive } & \text { Diagnosis codes (from index and previous admissions) } \\ \text { pulmonary disease } & 4273,42731,42732 \\ & \text { Diagnosis codes (from index and previous admissions) } \\ & 491,4910,4911,4912,49120,49121,49122,4918,4919,492,4920,4928,493,4930,49300,49301,49302,4931, \\ & 49310,49311,49312,4932,49320,49321,49322,4938,49380,49381,49382,4939,49390,49391,49392,\end{array}$


TABLE E2. Continued

Baseline characteristic

Chronic kidney disease

Liver disease
International Classification of Diseases, 9th Edition, Clinical Modification codes

Nondialysis-dependent

Diagnosis codes (from index and previous admissions)

403, 4030, 40300, 40301, 4031, 40310, 40311, 4039, 40390, 40391, 404, 4040, 40400, 40401, 40402, 40403, 4041, 40410, 40411, 40412, 40413, 4049, 40490, 40491, 40492, 40493, 582, 5820, 5821, 5822, 5824, 5828, $58281,58289,5829,583,5830,5831,5832,5834,5836,5837,5838,58381,58389,5839,585,5851,5852$, $5853,5854,5855,5859,586,587,588,5880,5881,5888,58881,58888,5889$, V420, and V56

Dialysis-dependent

Diagnosis codes (from index and previous admissions)

V451, V4511, V4512, V560, V561, V562, V563, V5631, V5632, V568, and 5856

Diagnosis codes (from index and previous admissions)

070, 0700, 0701, 0702, 07020, 07021, 07022, 07023, 0703, 07030, 07031, 07032, 07033, 0704, 07041, 07042, 07043, 07044, 07049, 0705, 07051, 07052, 07053, 07054, 07059, 0706, 0707, 07070, 07071, 0709, 456, 4560, 4561, 4562, 45620, 45621, 4563, 4564, 4565, 4566, 4568, 570, 571, 5710, 5711, 5712, 5713, 5714, 57140, $57141,57142,57149,5715,5716,5718,5719,572,5720,5721,5722,5723,5724,5728,573,5730,5731,5732$, $5733,5734,5735,5738,5738,7824,7891,7895,78951,78959,7904,7905,7948$, and V427

Cancer Oropharyngeal cancers

Diagnosis codes (from index and previous admissions)

$140,1400,1401,1403,1404,1405,1406,1408,1409,141,1410,1411,1412,1413,1414,1415,1416,1418,1419$, $142,1420,1421,1422,1428,1429,143,1430,1431,1438,1439,144,1440,1441,1448,1449,145,1450,1451$, $1452,1453,1454,1455,1456,1458,1459,146,1460,1461,1462,1463,1464,1465,1466,1467,1468,1469$, $147,1470,1471,1472,1473,1478,1479,148,1480,1481,1482,1483,1488,1489,149,1490,1491,1498$, and 1499

Gastrointestinal cancers

Diagnosis codes (from index and previous admissions)

$150,1500,1501,1502,1503,1504,1505,1506,1508,1509,1510,151,1511,15012,1513,1514,1515,1516$, $1518,1519,152,1520,1521,1522,1523,1528,1529,153,1530,1531,1532,1533,1534,1535,1536,1537$, $1538,1539,154,1540,1541,1542,1543,1548,155,1550,1551,1552,156,1560,1561,1562,1568,1569,157$, $1570,1571,1572,1573,1574,1578,1579,158,1580,1588,1589,159,1590,1591,1598$, and 1599

Respiratory tract cancers

Diagnosis codes (from index and previous admissions)

$160,1600,1601,1602,1603,1604,1605,1608,1609,161,1610,1611,1612,1613,1618,1619,162,1620,1622$, $1623,1624,1625,1628,1629,163,1630,1631,1638,1639,164,1640,1461,1462,1463,1468,1649,165$, 1650,1658 , and 1659

Bone and connective tissue cancer

Diagnosis codes (from index and previous admissions)

$170,1700,1701,1702,1703,1704,1705,1706,1707,1708,1709,171,1710,1712,1713,1714,1715,1716,1717$, $1718,1719,172,1720,1721,1722,1723,1724,1725,1726,1727,1728,1729,173,1730,17300,17301,17302$, 17309, 1731, 17310, 17311, 17312, 17319, 1732, 17320, 17321, 17322, 17329, 1733, 17330, 17331, 17332, 17339, 1734, 17340, 17341, 17342, 17349, 1735, 17350, 17351, 17352, 17359, 1736, 17360, 17361, 17362, 17369, 1737, 17370, 17371, 17372, 17379, 1738, 17380, 17381, 17382, 17389, 1739, 17390, 17391, 17392, $17399,174,1740,1741,1742,1743,1744,1745,1746,1748,1749,175,1750,1759,176,1760,1761,1762$, $1763,1764,1765,1768$, and 1769

Genitourinary cancers

Diagnosis codes (from index and previous admissions)

179, 180, 1800, 1801, 1808, 1809, 181, 182, 1820, 1821, 1828, 183, 1830, 1832, 1833, 1834, 1835, 1838, 1839, $184,1840,1841,1842,1843,1844,1848,1849,185,186,1860,1869,187,1871,1872,1873,1874,1875,1876$, $1877,1878,1879,188,1880,1881,1882,1883,1884,1885,1886,1887,1888,1889,189,1890,1891,1892$, 1893, 1894, 1898, and 1899

Lymphoid cancers

Diagnosis codes (from index and previous admissions)

200, 2000, 20000, 20001, 20002, 20003, 20004, 20005, 20006, 20007, 20008, 2001, 20010, 20011, 20012, 20013, 20014, 20015, 20016, 20017, 20018, 2002, 20020, 20021, 20022, 20023, 20024, 20025, 20026, 20027, 20028, 2003, 20030, 20031, 20032, 20033, 20034, 20035, 20036, 20037, 20038, 2004, 20040, 20041, 20042, 20043, 20044, 20045, 20046, 20047, 20048, 2005, 20050, 20051, 20052, 20053, 20054, 20055, 20056, 20057, 20058,

(Continued) 
TABLE E2. Continued

\begin{tabular}{|c|c|}
\hline Baseline characteristic & International Classification of Diseases, 9th Edition, Clinical Modification codes \\
\hline & 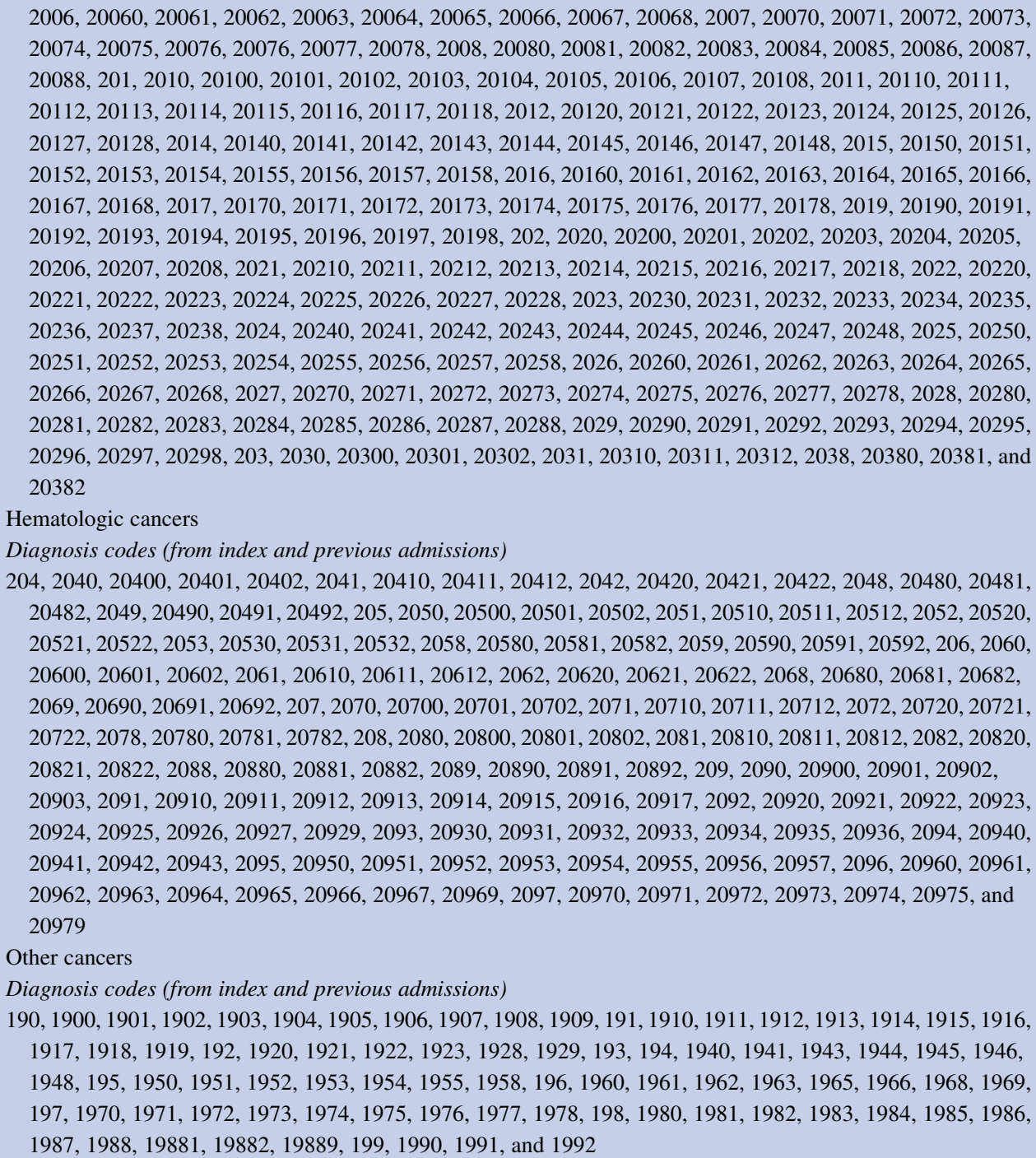 \\
\hline
\end{tabular}


TABLE E3. Definition of secondary endpoints

\begin{tabular}{|c|c|}
\hline Outcome & International Classification of Diseases, 9th Edition, Clinical Modification codes \\
\hline Stroke & $\begin{array}{l}\text { Iatrogenic stroke } \\
\text { Diagnosis code (from index hospitalization) } \\
99702 \\
\text { Hemorrhagic stroke } \\
\text { Diagnosis codes (primary diagnosis of subsequent admissions) } \\
430,431,432,4320,4321 \text {, and } 4329 \\
\text { Ischemic stroke } \\
\text { Diagnosis codes (primary diagnosis of subsequent admissions) } \\
43301,43311,43321,43331,43381,43391,43401,43411 \text {, and } 43491\end{array}$ \\
\hline Reoperation & $\begin{array}{l}\text { Procedure codes (subsequent admissions) } \\
3523 \text { and } 3524\end{array}$ \\
\hline Major bleeding event & $\begin{array}{l}\text { Intracerebral hemorrhage } \\
\text { Diagnosis codes (primary diagnosis of subsequent admission) } \\
430,431,432,4320,4321, \text { and } 4329 \\
\text { Hemopericardium or cardiac tamponade } \\
\text { Diagnosis codes (primary diagnosis of subsequent admission) } \\
4230 \text { and } 4233 \\
\text { Gastrointestinal hemorrhage } \\
\text { Diagnosis codes (primary diagnosis of subsequent admission) } \\
4560,45620,4590,53021,5310,53100,53101,5312,53120,53121,5314,53140,53141,5316,53160,53161,5320,53200, \\
53201,5322,53220,53221,53241,5326,53260,53261,5330,53300,53301,5332,53320,53321,53340,533401,5336, \\
53360,53361,5340,53400,53401,5342,53420,53421,5344,53440,53441,5346,53501,53511,53521,53531,53541, \\
53561,53571,5693,578,5780,5781, \text { and } 5789 \\
\text { Hematuria } \\
\text { Diagnosis codes (primary diagnosis of subsequent admission) } \\
5997,59970, \text { and 59971 } \\
\text { Hemarthrosis } \\
\text { Diagnosis codes (primary diagnosis of subsequent admission) } \\
7191,71910,71911,71912,71913,71914,71915,71916,71917,71918, \text { and } 71919 \\
\text { Hemoptysis } \\
\text { Diagnosis codes (primary diagnosis of subsequent admission) } \\
7848,7863,78630, \text { and } 78639 \\
\text { Epistaxis } \\
\text { Diagnosis codes (primary diagnosis of subsequent admission) } \\
7847 \\
\text { Retinal or choroidal hemorrhage } \\
\text { Diagnosis codes (primary diagnosis of subsequent admission) } \\
\text { 36281, 36243, 36361, and } 36362\end{array}$ \\
\hline
\end{tabular}


TABLE E4. Definition of 30-day complications

\begin{tabular}{|c|c|}
\hline Outcome & International Classification of Diseases, 9th Edition, Clinical Modification codes \\
\hline Stroke & $\begin{array}{l}\text { Diagnosis code (from index admission) } \\
99702 \\
\text { Diagnosis codes (from subsequent admissions) } \\
430,431,432,4320,4321,4329,43301,43311,43321,43331,43381,43391,43401,43411 \text {, and } 43491\end{array}$ \\
\hline Atrial fibrillation & $\begin{array}{l}\text { Diagnosis code (from index and subsequent admissions) } \\
4273,42731 \text {, and } 42732\end{array}$ \\
\hline Acute kidney injury & $\begin{array}{l}\text { Diagnosis code (from index and subsequent admissions) } \\
5939,584,5845,5846,5847,5848 \text {, and } 5849\end{array}$ \\
\hline Respiratory failure & 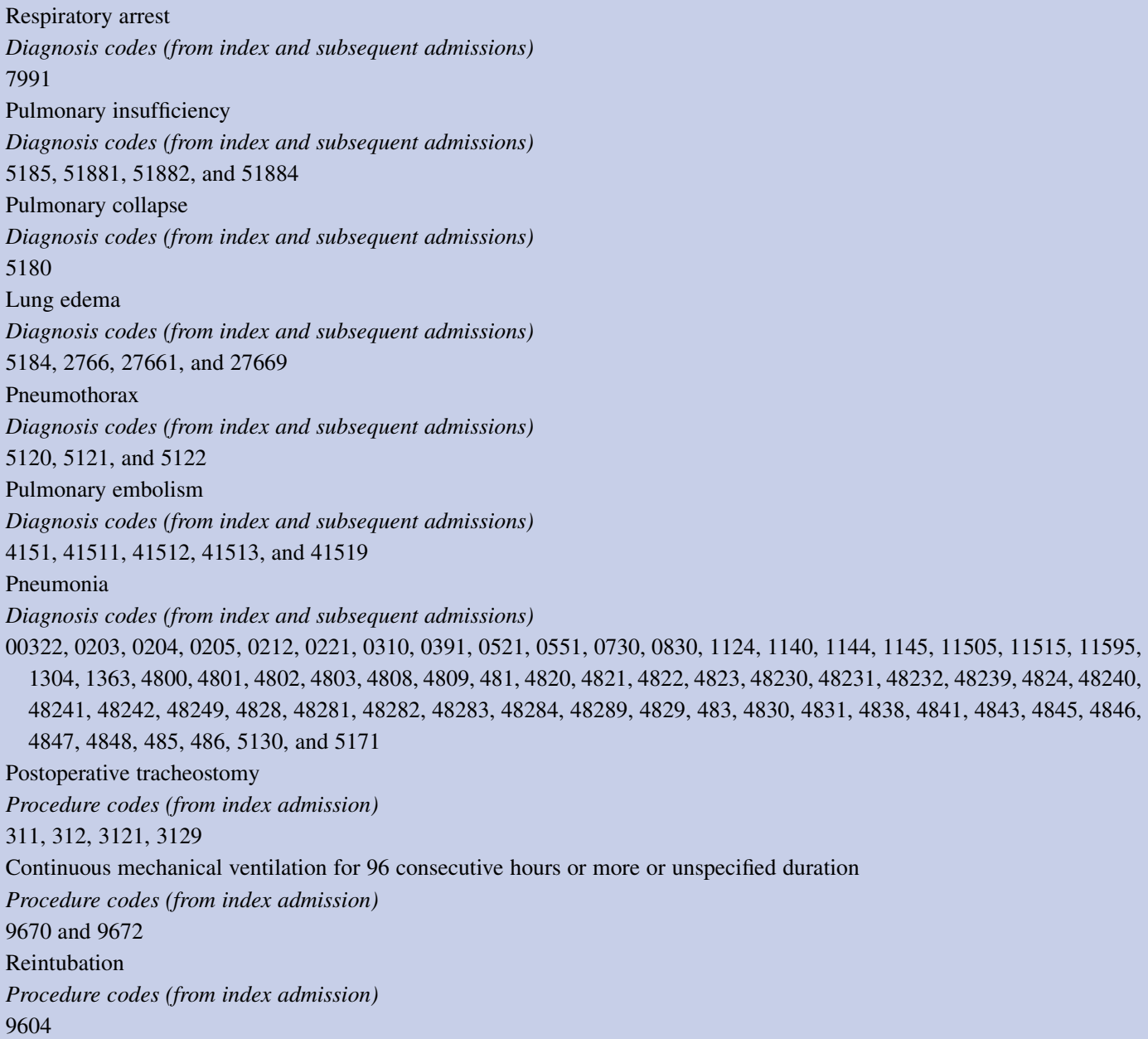 \\
\hline
\end{tabular}


TABLE E5. Multivariable Cox regression analysis results of each endpoint in the full study cohort: survival, stroke, major bleeding, and reoperation

\begin{tabular}{|c|c|c|c|}
\hline Variable & Hazard ratio & $95 \%$ confidence interval & $P$ value \\
\hline \multicolumn{4}{|l|}{ Survival } \\
\hline Bioprosthesis & 1.39 & $1.05-1.83$ & .02 \\
\hline Age & 1.02 & $1.01-1.03$ & .009 \\
\hline Male sex & 0.94 & $0.77-1.14$ & .51 \\
\hline \multicolumn{4}{|l|}{ Race } \\
\hline White & 1.00 & - & - \\
\hline African-American & 1.20 & $0.95-1.52$ & .13 \\
\hline Other & 0.82 & $0.66-1.02$ & .07 \\
\hline Emergent/urgent admission & 1.08 & $0.89-1.32$ & .43 \\
\hline NY State residency & 0.81 & $0.66-1.00$ & .05 \\
\hline Coagulation/platelet disorders & 1.06 & $0.68-1.64$ & .80 \\
\hline Hypertension & 1.61 & $1.27-2.03$ & $<.001$ \\
\hline Diabetes mellitus & 1.41 & $1.06-1.88$ & .02 \\
\hline Coronary artery disease & 1.32 & $1.04-1.67$ & .02 \\
\hline Peripheral vascular disease & 1.96 & $1.27-3.02$ & .003 \\
\hline Cerebrovascular disease & 1.02 & $0.75-1.39$ & .89 \\
\hline Congestive heart failure & 1.23 & $0.99-1.51$ & .06 \\
\hline Atrial fibrillation & 1.12 & $0.93-1.34$ & .24 \\
\hline Chronic obstructive pulmonary disease & 1.92 & $1.60-2.30$ & $<.001$ \\
\hline Dialysis dependency & 3.70 & $2.60-5.26$ & $<.001$ \\
\hline Liver disease & 1.44 & $0.98-2.10$ & .06 \\
\hline Cancer & 3.34 & $2.18-5.13$ & $<.001$ \\
\hline Year of surgery & 0.94 & $0.90-0.97$ & $<.001$ \\
\hline \multicolumn{4}{|l|}{ Stroke } \\
\hline Bioprosthesis & 0.87 & $0.60-1.27$ & .47 \\
\hline Age & 1.01 & $0.99-1.03$ & .20 \\
\hline Male sex & 0.80 & $0.60-1.08$ & .15 \\
\hline \multicolumn{4}{|l|}{ Race } \\
\hline White & 1.00 & - & - \\
\hline African-American & 1.42 & $1.04-1.94$ & .03 \\
\hline Other & 1.16 & $0.83-1.62$ & .40 \\
\hline Emergent/urgent Admission & 0.88 & $0.64-1.22$ & .45 \\
\hline NY State residency & 0.64 & $0.50-0.83$ & $<.001$ \\
\hline Coagulation/platelet disorders & 1.25 & $0.66-2.37$ & .49 \\
\hline Hypertension & 1.65 & $1.21-2.25$ & .001 \\
\hline Diabetes mellitus & 1.38 & $0.87-2.21$ & .18 \\
\hline Coronary artery disease & 0.94 & $0.67-1.33$ & .74 \\
\hline Peripheral vascular disease & 0.56 & $0.13-2.35$ & .43 \\
\hline Cerebrovascular disease & 1.64 & $1.04-2.57$ & .03 \\
\hline Congestive heart failure & 1.34 & $1.02-1.78$ & .04 \\
\hline Atrial fibrillation & 1.02 & $0.80-1.30$ & .88 \\
\hline Chronic obstructive pulmonary disease & 1.28 & $0.94-1.74$ & .12 \\
\hline Dialysis dependent & 1.05 & $0.50-2.23$ & .90 \\
\hline Liver disease & 0.67 & $0.35-1.27$ & .22 \\
\hline Cancer & 1.70 & $0.78-3.69$ & .18 \\
\hline Year of surgery & 1.02 & $0.97-1.07$ & .46 \\
\hline \multicolumn{4}{|l|}{ Major bleeding } \\
\hline Bioprosthesis & 0.72 & $0.46-1.12$ & .15 \\
\hline Age & 1.03 & $1.00-1.05$ & .02 \\
\hline Male sex & 0.72 & $0.53-0.97$ & .03 \\
\hline
\end{tabular}

(Continued) 
TABLE E5. Continued

\begin{tabular}{|c|c|c|c|}
\hline Variable & Hazard ratio & $95 \%$ confidence interval & $P$ value \\
\hline \multicolumn{4}{|l|}{ Race } \\
\hline White & 1.00 & - & - \\
\hline African-American & 0.94 & $0.63-1.41$ & .78 \\
\hline Other & 1.13 & $0.86-1.50$ & .37 \\
\hline Emergent/urgent admission & 0.95 & $0.68-1.32$ & .75 \\
\hline NY State residency & 0.87 & $0.67-1.13$ & .28 \\
\hline Coagulation/platelet disorders & 1.44 & $0.90-2.31$ & .13 \\
\hline Hypertension & 1.17 & $0.87-1.57$ & .31 \\
\hline Diabetes mellitus & 1.54 & $1.00-2.37$ & .05 \\
\hline Coronary artery disease & 0.90 & $0.63-1.29$ & .58 \\
\hline Peripheral vascular disease & 1.76 & $0.84-3.68$ & .13 \\
\hline Cerebrovascular disease & 1.45 & $0.90-2.34$ & .13 \\
\hline Congestive heart failure & 1.65 & $1.20-2.28$ & .003 \\
\hline Atrial fibrillation & 0.95 & $0.73-1.23$ & .68 \\
\hline Chronic obstructive pulmonary disease & 1.24 & $0.93-1.64$ & .14 \\
\hline Dialysis dependent & 2.74 & $1.59-4.74$ & $<.001$ \\
\hline Liver disease & 1.20 & $0.73-1.95$ & .48 \\
\hline Cancer & 2.03 & $1.04-3.94$ & .38 \\
\hline Year of surgery & 0.98 & $0.94-1.03$ & .44 \\
\hline \multicolumn{4}{|l|}{ Mitral reoperation } \\
\hline \multicolumn{4}{|l|}{ Bioprosthesis } \\
\hline $5 \mathrm{y}$ & 3.39 & $2.35-4.89$ & $<.001$ \\
\hline $10 \mathrm{y}$ & 6.43 & $3.99-10.4$ & $<.001$ \\
\hline $15 \mathrm{y}$ & 12.2 & $5.77-25.8$ & $<.001$ \\
\hline Age & 0.97 & $0.95-0.98$ & $<.001$ \\
\hline Male sex & 0.89 & $0.64-1.22$ & .46 \\
\hline \multicolumn{4}{|l|}{ Race } \\
\hline White & 1.00 & - & - \\
\hline African-American & 1.05 & $0.68-1.61$ & .84 \\
\hline Other & 0.60 & $0.43-0.85$ & .003 \\
\hline Emergent/urgent admission & 1.01 & $0.72-1.42$ & .94 \\
\hline NY State residency & 0.94 & $0.68-1.31$ & .73 \\
\hline Coagulation/platelet disorders & 1.53 & $0.79-2.95$ & .21 \\
\hline Hypertension & 1.57 & $1.11-2.20$ & .01 \\
\hline Diabetes mellitus & 0.60 & $0.28-1.29$ & .19 \\
\hline Coronary artery Disease & 1.33 & $0.87-2.03$ & .19 \\
\hline Peripheral vascular disease & 2.00 & $0.66-6.10$ & .22 \\
\hline Cerebrovascular disease & 0.70 & $0.36-1.35$ & .29 \\
\hline Congestive heart failure & 0.85 & $0.63-1.15$ & .29 \\
\hline Atrial fibrillation & 0.93 & $0.64-1.34$ & .68 \\
\hline Chronic obstructive pulmonary disease & 0.98 & $0.59-1.63$ & .95 \\
\hline Dialysis dependent & 2.12 & $1.06-4.24$ & .03 \\
\hline Liver disease & 0.61 & $0.28-1.35$ & .23 \\
\hline Cancer & 1.80 & $0.81-4.03$ & .15 \\
\hline Year of surgery & 1.01 & $0.94-1.08$ & .89 \\
\hline
\end{tabular}


TABLE E6. Patient baseline characteristics in the overall cohort and by type of prosthesis

\begin{tabular}{|c|c|c|c|c|c|}
\hline \multirow[b]{2}{*}{ Baseline characteristics } & \multicolumn{3}{|c|}{ Prosthesis type, n (\%) } & \multirow[b]{2}{*}{ Standardized difference $(\%)$} & \multirow[b]{2}{*}{$P$ value } \\
\hline & $\begin{array}{l}\text { All patients } \\
(N=2727)\end{array}$ & $\begin{array}{c}\text { Bioprosthetic } \\
\quad(\mathbf{n}=\mathbf{3 8 2})\end{array}$ & $\begin{array}{c}\text { Mechanical } \\
(\mathrm{n}=2345)\end{array}$ & & \\
\hline \multicolumn{6}{|l|}{ Demographics } \\
\hline Age, median [IQR], y & $43[38-47]$ & $42[36-47]$ & 43 [38-47] & 17.4 & .005 \\
\hline $18-30$ & $237(8.7)$ & $52(13.6)$ & $185(7.9)$ & & .001 \\
\hline $31-40$ & $750(27.5)$ & $101(26.4)$ & 649 (27.7) & & \\
\hline $41-50$ & $1740(63.8)$ & $229(59.9)$ & $1511(64.4)$ & & \\
\hline Men & $1076(39.5)$ & $143(37.4)$ & $933(39.8)$ & 4.8 & .38 \\
\hline New York State resident & $1293(47.4)$ & $216(56.5)$ & $1077(45.9)$ & 21.4 & $<.001$ \\
\hline \multicolumn{6}{|l|}{ Race/ethnicity } \\
\hline White (non-Hispanic) & $1437(52.7)$ & $188(49.2)$ & $1249(53.3)$ & 8.1 & .09 \\
\hline African-American (non-Hispanic) & $416(15.3)$ & $72(18.8)$ & $344(14.7)$ & 11.2 & \\
\hline Other & $874(32.0)$ & $122(31.9)$ & $752(32.1)$ & 0.3 & \\
\hline Emergent/urgent admission & $772(28.3)$ & $149(39.0)$ & $623(26.6)$ & 26.7 & $<.001$ \\
\hline \multicolumn{6}{|l|}{ Comorbidities } \\
\hline Coagulation/platelet disorders & $112(4.1)$ & $20(5.2)$ & $92(3.9)$ & 6.3 & .23 \\
\hline Hypertension & $791(29.0)$ & $103(27.0)$ & $688(29.3)$ & 5.3 & .34 \\
\hline Diabetes mellitus & $188(6.9)$ & $28(7.3)$ & $160(6.8)$ & 2.0 & .72 \\
\hline Coronary artery disease & $433(15.9)$ & $69(18.1)$ & $364(15.5)$ & 6.8 & .21 \\
\hline Peripheral vascular disease & $48(1.8)$ & $6(1.6)$ & $42(1.8)$ & 1.7 & .76 \\
\hline Cerebrovascular disease & $165(6.1)$ & $30(7.9)$ & $135(5.8)$ & 8.3 & .11 \\
\hline Congestive heart failure & $1329(48.7)$ & $193(50.5)$ & $1136(48.4)$ & 4.2 & .45 \\
\hline Atrial fibrillation & $910(33.4)$ & $94(24.6)$ & $816(34.8)$ & 22.4 & $<.001$ \\
\hline Chronic obstructive pulmonary disease & $417(15.3)$ & $70(18.3)$ & $347(14.8)$ & 9.5 & .08 \\
\hline Chronic kidney disease & $154(5.6)$ & $26(6.8)$ & $128(5.5)$ & 5.6 & .29 \\
\hline Dialysis dependent & $114(4.2)$ & $17(4.5)$ & $97(4.1)$ & 1.6 & .78 \\
\hline Liver disease & $148(5.4)$ & $22(5.8)$ & $126(5.4)$ & 1.7 & .76 \\
\hline Cancer & $64(2.3)$ & $14(3.7)$ & $50(2.1)$ & 9.2 & .07 \\
\hline \multicolumn{6}{|l|}{ Year of surgery } \\
\hline 1997 & $346(12.7)$ & $35(9.2)$ & $311(13.3)$ & 13.0 & $<.001$ \\
\hline 1998 & $313(11.5)$ & $22(5.8)$ & $291(12.4)$ & 23.3 & \\
\hline 1999 & $291(10.7)$ & $28(7.3)$ & $263(11.2)$ & 13.4 & \\
\hline 2000 & $262(9.6)$ & $39(10.2)$ & $223(9.5)$ & 2.4 & \\
\hline 2001 & $287(10.5)$ & $43(11.3)$ & $244(10.4)$ & 2.7 & \\
\hline 2002 & $294(10.8)$ & $35(9.2)$ & 259 (11.0) & 6.3 & \\
\hline 2003 & $264(9.7)$ & $28(7.3)$ & $236(10.1)$ & 9.7 & \\
\hline 2004 & $233(8.5)$ & $56(14.7)$ & $177(7.5)$ & 22.8 & \\
\hline 2005 & $245(9.0)$ & $63(16.5)$ & $182(7.8)$ & 27.0 & \\
\hline 2006 & $192(7.0)$ & $33(8.6)$ & $159(6.8)$ & 7.0 & \\
\hline
\end{tabular}

$I Q R$, Interquartile range. 